\title{
Long Term Results of Epiphyseal Transplant in Distal Radius Reconstruction in Children
}

\author{
Langzeitergebnisse nach freier Epiphysen-Transplantion bei Kindern zur \\ Rekonstruktion des distalen Radius
}

Authors

Affiliation

\author{
M. Innocenti, C. Baldrighi, G. Menichini
}

Plastic Reconstructive Surgery and Microsurgery, Oncology, University Hospital Careggi СTO, Firenze, Italy

Key words
microsurgery
hand surgery
tumors
interdisciplinary cooperation
plastic surgery
Free Fibula Flap
Schlüsselwörter
Mikrochirurgie
Handchirurgie
Tumore
interdisziplinäre Kooperation
plastische Chirurgie
Freie Fibula-Lappenplastik

received $\quad 21.12 .2014$

accepted $\quad 9.2 .2015$

\section{Bibliography}

DOI http://dx.doi.org/ $10.1055 / \mathrm{s}-0035-1547304$

Handchir Mikrochir Plast Chir 2015; 47: 83-89

(c) Georg Thieme Verlag KG

Stuttgart · New York

ISSN 0722-1819

\section{Correspondence}

Dr. Carla Baldrighi

Plastic Reconstructive Surgery

and Microsurgery

Oncology

University Hospital Careggi СТО

Firenze

50134 Italy

carlabaldrighi@gmail.com

\section{Abstract}

$\nabla$

Background: Replacement of osseous defect, restoration of joint function, and restoration of longitudinal growth are the 3 main reconstructive issues that need to be addressed when the physis and epiphysis are damaged in a skeletally immature individual. Failure in achieving these objectives leads to severe deformity and functional impairment, which significantly compromises the quality of life of young patients. Because of its biological and morphological characteristics, the proximal fibula epiphyseal transfer has proven to be an excellent option in limb salvage surgery in pediatric oncologic cases meeting all the reconstructive requirements.

Methods: Between 1992-2006, 8 children with a mean age of 7.3 years (range $4-11$ years old) diagnosed with malignant bone tumor of the distal radius underwent tumor resection and immediate microsurgical reconstruction of the distal part of the radius with vascularized proximal fibular transfer, which included the physis and a variable length of the diaphysis. The anterior tibial vascular network supplied all of the grafts. One patient died to lung metastasis, 3.5 years after surgery; a second patient was lost at followup. The remaining 6 patients were periodically followed up both clinically, measuring range of motion, grip strength and the sensation of the hand, and by means of standard $x$ rays, bone scan and CT scan.

Results: The mean follow-up was 13.2 years (range, 8-22 years). All the transfers survived and underwent fusion at the recipient site. In our experience the fibular growth expected after the transplant, ranges between 0.7 and $1.4 \mathrm{~cm}$ per year. In this series growth arrest occurred in only one patient after trauma. Serial radiographs and CT scans revealed progressive remodeling over time of the new articular surface. The functional result was rated as excellent in all but the

\section{Zusammenfassung \\ $\nabla$}

Hintergrund: Die 3 wichtigsten Ziele einer erfolgreichen Rekonstruktion nach Verletzung der Epiphysenfuge und der Epiphyse in Patienten mit noch nicht ausgewachsenem Skelett sind Ersatz des Knochendefekts, Wiederherstellung der Gelenkfunktion sowie gleichzeitig Wiederherstellung des Längenwachstums. Gelingt es nicht, diese Ziele zu erreichen, können schwere Deformierungen und Funktionseinschränkungen die Folgen sein, welche die Lebensqualität junger Patienten stark beeinträchtigen können. Die freie, mikrovaskuläre Transplantation der Epiphyse des proximalen Wadenbeins hat sich aufgrund seiner biologischen und morphologischen Eigenschaften als hervorragende Wahl bei der Extremitäten erhaltenden Chirurgie in der pädiatrischen Onkologie erwiesen. Diese Art der plastisch-chirurgischen Behandlung erfüllt alle Rekonstruktionsanforderungen.

Patineten und Methoden: Zwischen 19922006 wurde bei 8 Kindern (mittleres Alter: 7,3 Jahren; Spannweite: 4-11 Jahre) eine einzeitige mikrochirurgische Sofortrekonstruktion des distalen Radius nach Resektion eines Malignoms des distalen Radius durchgeführt. Für die Rekonstruktion wurde ein vaskularisierter Teil des Wadenbeins bestehend aus Epiphysenfuge und unterschiedlicher Diaphysenlänge verwendet. Alle Transplantate wurden an die gefäße der A.tibialis anterior mikrovaskulär anastomosiert. Ein Patient ist dreieinhalb Jahren nach der Operation an den Folgen einer Lungenmetastasierung verstorben. Ein zweiter Patient konnte nicht nach untersucht werden. Die verbleibenden 6 Patienten wurden in regelmäßigen Abständen untersucht. Bei der klinischen Nachuntersuchung wurden Bewegungsradius, Greifkraft und Sensibiltät der Hand geprüft; Röntgenaufnahmen, Knochenszintigrafie und Computertomografie wurden bei allen nachbeobachteten Kindern durchgeführt. 
one patient, in whom the distal portion of the ulna had to be resected because of tumor invasion. No major complication occurred at the recipient site. Peroneal nerve palsy occurred at the or site in 3 patients. The palsy was transient in 2 patients, but it persisted in one. No instability of the knee joint was observed.

Conclusions: Our long-term results confirm that a vascularized transfer of the proximal fibula provides a reliable and durable reconstruction of the distal radius in children. Even after 22 years, the reconstructed joint resulted to be free of pain and degenerative changes thus maintaining a nearly normal range of motion. The described procedure is therefore highly recommended in case of distal radius reconstruction in growing children.
Ergebnisse: Die mittlere Nachbeobachtungszeit betrug 13,2 Jahre (8-22 Jahre). Die Transplantate haben in allen Patienten überlebt und zeigten Knochenfusion an der Empfängerstelle. Nach unseren Erfahrungen beträgt das nach einer Transplantation zu erwartende Wadenbeintransplantat-Wachstum zwischen 0,7 und 1,4 Zentimeter im Jahr. In dieser Patientenserie gab es nur einen Fall mit Wachstumsstillstand nach Trauma. Röntgenreihenuntersuchungen und Computertomografie zeigten im Laufe der Zeit fortschreitendes Remodelling an der Oberfläche des Gelenkfortsatzes. Das funktionale Ergebnis wurde bei allen außer in einem Patienten als hervorragend bewertet; bei diesem Patienten musste der distale Anteil der Elle wegen Tumorinvasion reseziert werden. Es gab keine wesentlichen Komplikationen an der Empfängerstelle. Drei Patienten erlitten eine Peronäusparese an der Entnahmestelle. In 2 Patienten war die Parese vorübergehend, in einem Patienten persistierte sie. Es wurde keine Instabilität des Kniegelenks beobachtet.

Schlussfolgerung: Unsere Langzeitergebnisse zeigen, dass der vaskularisierte Transfer des proximalen Wadenbeins eine zuverlässige und dauerhafte Rekonstruktion des distalen Radius bei Kindern ermöglicht. Selbst nach 22 Jahren blieb das rekonstruierte Gelenk schmerzfrei und ohne degenerative Veränderungen und der Bewegungsradius fast normal. Die hier beschriebene Operation ist daher besonders zur Rekonstruktion des distalen Radius in heranwachsenden Kindern geeignet.

massive neoplastic invasion, and in one patient also the adjacent distal ulna was resected. The resulting bone defect in the distal radius was reconstructed using a vascularized transfer of the proximal fibula harvested on the anterior tibial artery. A preoperative angiogram was routinely performed in order to assess the location and the size of the recurrent epiphyseal branch. Protecting this branch is the key point of the surgery, as damage to it would hinder the future growth of the transferred proximal fibula ( $\bullet$ Fig. 1).

One patient died due to lung metastasis, 3.5 years after surgery; a second patient was lost to follow-up. The remaining 6 patients were periodically followed up both clinically, measuring range of motion, grip strength and the sensation of the hand, and by means of standard X-rays, bone scan and CT scan.

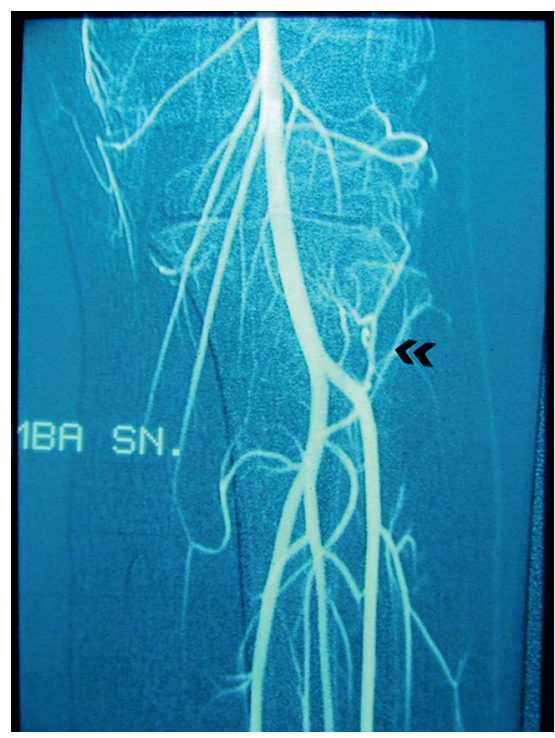

Fig. 1 Preoperative angiogram is routinely performed to assess the location and the size of the recurrent epiphyseal branch.

\section{Patients, Materials and Methods \\ Patients}

Between 1992 and 2006, 8 children with a mean age of 7.3 years (range: 4-11 years) underwent limb salvage surgery for osteogenic or Ewing sarcoma involving the distal radius. The mean follow-up was 13.2 years (range: 8-22 years). Preoperative and postoperative chemotherapy was administered to all patients according to the different protocols in use at the time of diagnosis for osteogenic sarcoma and Ewing sarcoma. In all cases the entire distal radius along with a variable amount of the diaphysis was resected. In 2 cases the whole radius was resected, due to 


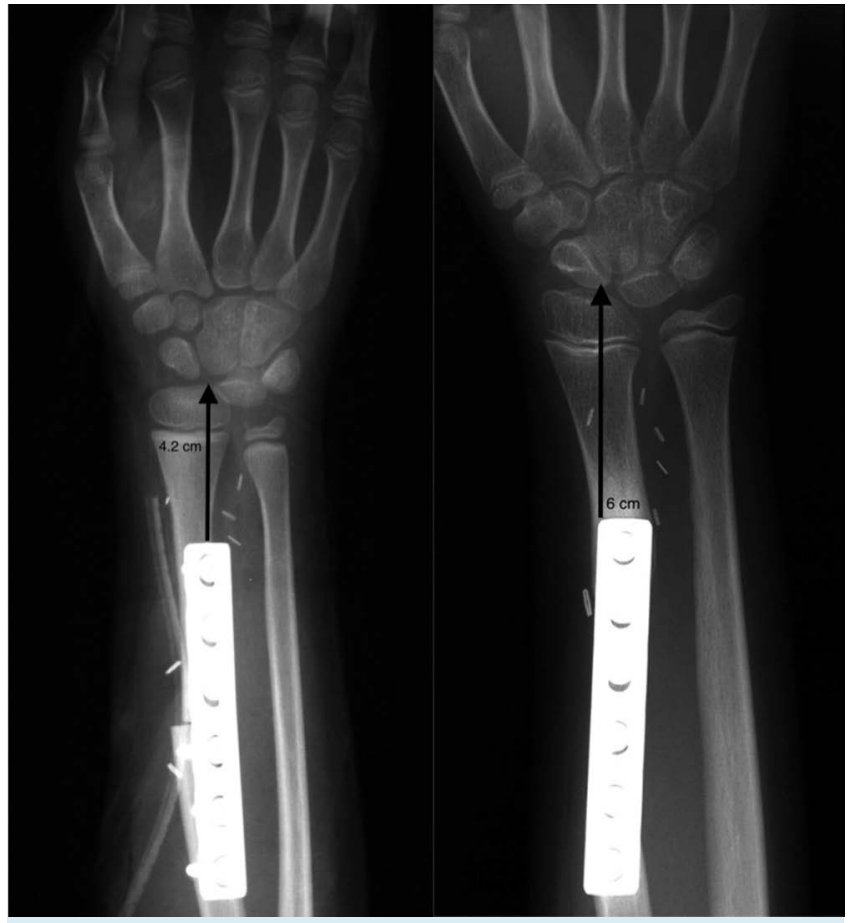

Fig. 2 The growth of the transferred bones is assessed on X-ray measuring the distance between the tip of the physis and the distal end of the metal plate used for bone fixation. When growth occurs the distance between these 2 points progressively increases.

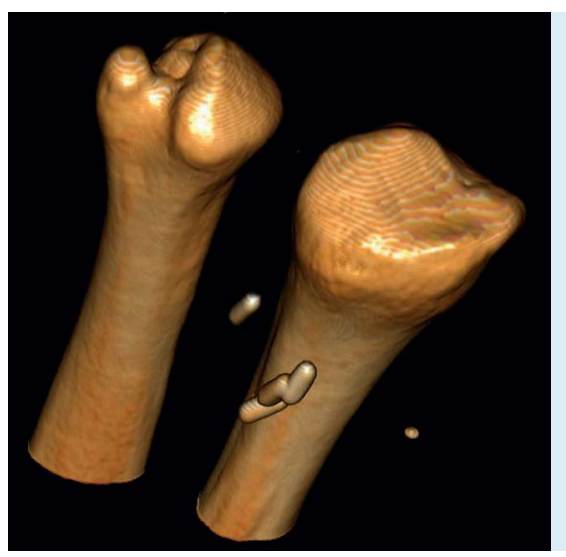

Fig. 3 Threedimensional C.T. scan imaging monitors the progressive morphological modifications of the epiphysis and the articular surface under the influence of the new loading stresses at the recipient site.

The growth of the transferred bones was evaluated radiologically assessing the distance between 2 given landmarks: the tip of the physis and the distal end of the metal plate (or screw) used for bone fixation. When growth occurs the distance between these 2 points progressively increases ( $\bullet$ Fig. $\mathbf{2 a}, \mathbf{b}$ ). Three-dimensional CT scan imaging was also useful to monitor the progressive morphological modifications of the epiphysis and the articular surface under the influence of the new loading stresses at the recipient site ( $\bullet$ Fig. $\mathbf{3}$ ).

\section{Operative technique}

The surgical technique of vascularized proximal fibula graft based on the anterior tibial artery vascular network has been recently refined $[1,2]$. We modified the original description by Taylor in 1988 [3], introducing a reverse flow concept, which provides a much longer distal vascular pedicle and avoids the need of vein grafts.

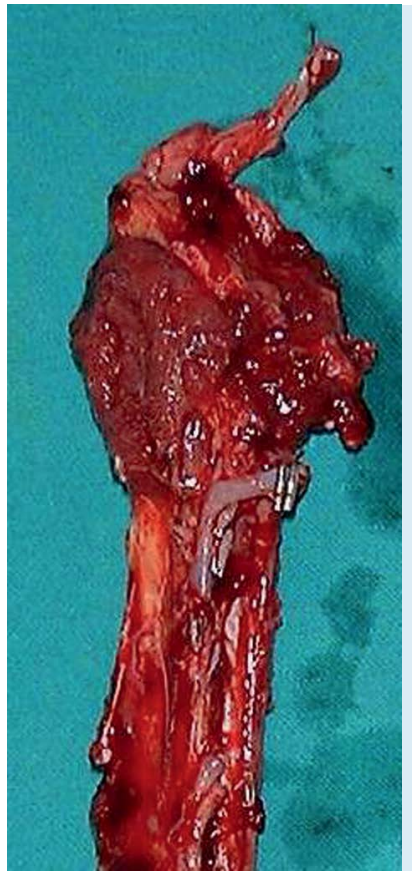

Fig. 4 The epiphyseal recurrent branch of the anterior tibial artery is protected during the dissection by leaving a muscular cuff of extensor digitorum longus and peroneus longus muscles proximal to the intersection of peroneal nerve around the head of the fibula.

The fibula and its vascular pedicle (anterior tibialis vessels) are exposed through an anterolateral approach that develops in the space between tibialis anterior and extensor digitorum longus muscles. The incision is then prolonged proximally and laterally, in an $S$ shaped fashion, up to the biceps femoris tendon. Great care must be taken in dissecting the peroneal nerve from the anterior tibialis vascular bundle and in preserving the musculoperiosteal branches to the diaphysis of the fibula. Direct dissection of the epiphyseal recurrent branch is to be avoided because the small caliber of this artery might expose the surgeon to a great risk of injuring it.

This small vessel must be protected by a muscular cuff ( $\bullet$ Fig. 4) of the extensor digitorum longus and peroneus longus muscles, which are proximal to the intersection of peroneal nerve. A strip of biceps femoris tendon is also harvested attached to the proximal fibula and used later for soft tissue repair at the recipient site.

Distal radius reconstruction is facilitated by the excellent congruency in size between the diaphysis of the graft and the recipient bone. Plates and screws usually achieve bone fixation and the pedicle is anastomosed in an end-to-end fashion either to the anterior interosseous or the radial artery and cephalic vein. Bleeding from the muscular cuff surrounding the epiphysis, after microvascular repair, indicates the restoration of an adequate flow to the growth plate.

The radio-carpal joint is stabilized using the biceps femoris tendon strip, which is woven into the residual distal capsule. Conversely, no attempt was ever made to stabilize the new DRUJ. In the absence of the sigmoid notch in the new distal radius a tight stabilization of the caput ulnae would be biomechanically unfavorable, leading to a possible reduction of pronation/ supination. In 2 cases, the resection of the entire radius forced us to fixate the proximal stump of the fibula to the adjacent ulna, creating a radioulnar synostosis. Bone stability was achieved but prono-supination was lost. In one case where also the ulna was resected, the fibula was fused to the proximal stump of the ulna to obtain a one-bone forearm. 

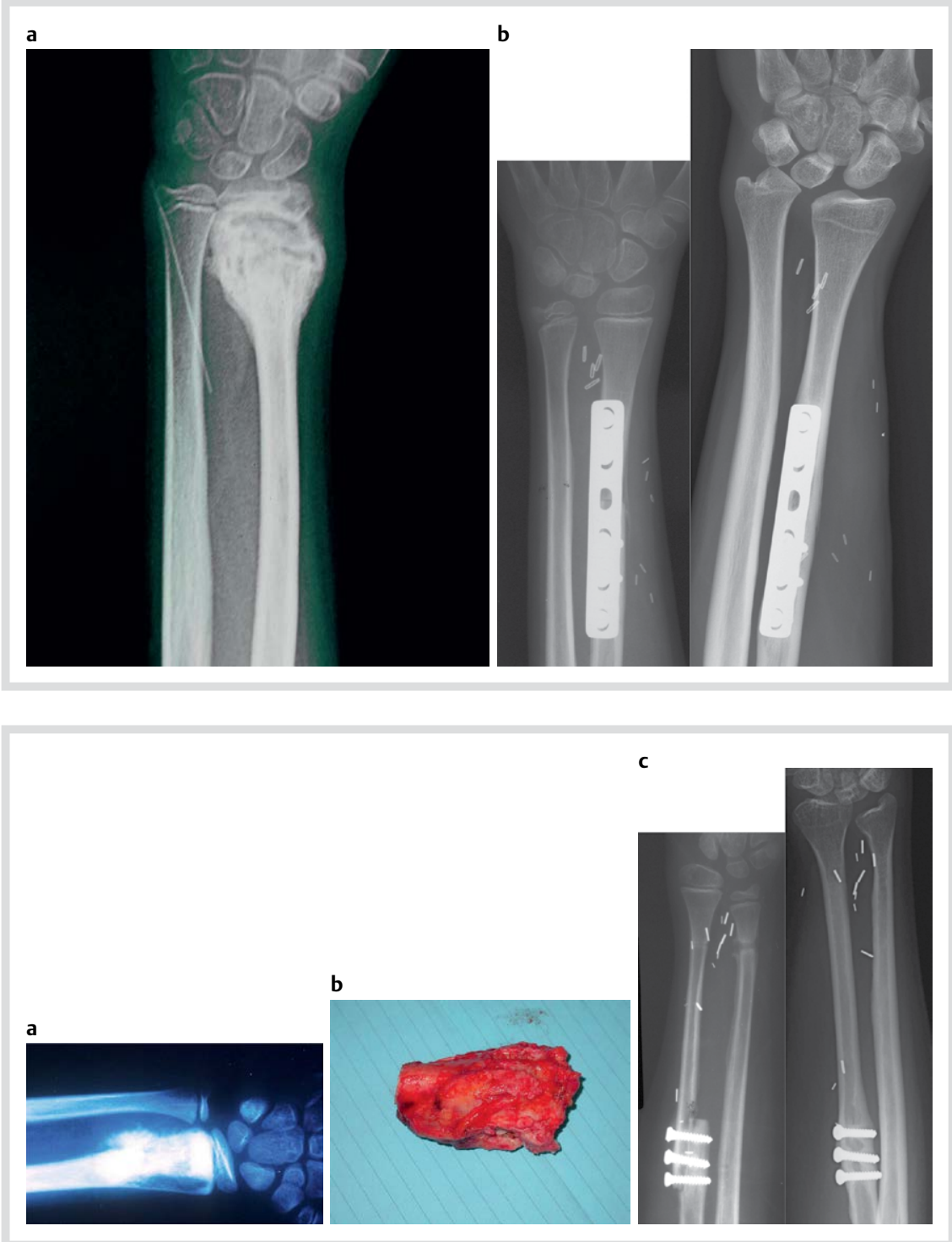

Fig. 5 a Preoperative $X$-ray; $b$ In our series the fibular growth after the transplant ranges between 0.7 and $1.4 \mathrm{~cm}$ per year depending on several factors.

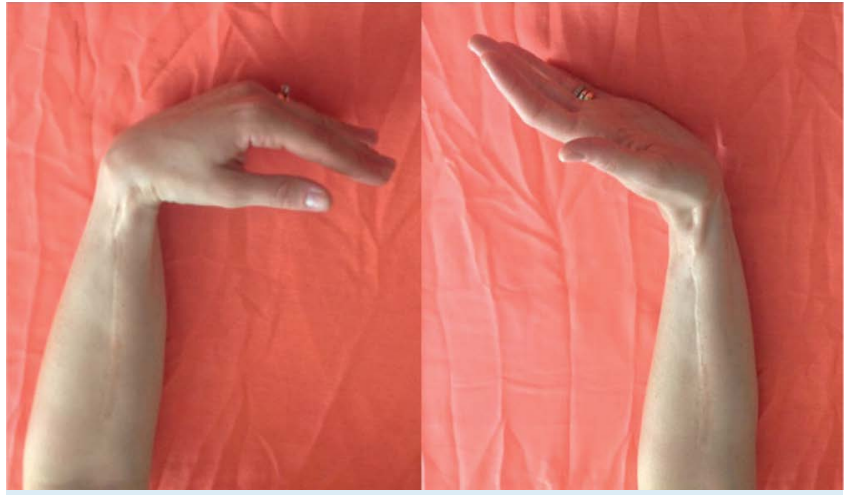

Fig. 7 Satisfying functional outcomes with nearly normal range of motion after physiological 2-bone forearm reconstruction.

\section{Results}

$\nabla$

In our experience the fibular growth expected after the transplant ranges between 0.7 and $1.4 \mathrm{~cm}$ per year ( $\bullet$ Fig. 5a, b, - $6 a-c)$. In this series of patients, only one growth arrest was observed after a fracture.
Fig. 6 a Preoperative $X$-ray; b specimen of the resected tumor; $c$ In our series the fibular growth after the transplant ranges between 0.7 and $1.4 \mathrm{~cm}$ per year depending on several factors. In our series the fibular growth after the transplant ranges between 0.7 and $1.4 \mathrm{~cm}$ per year depending on several factors. 


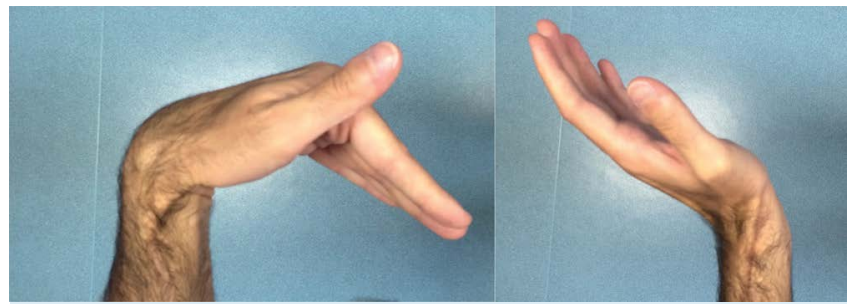

Fig. 8 Satisfying functional outcomes with nearly normal range of motion after physiological 2-bone forearm reconstruction.

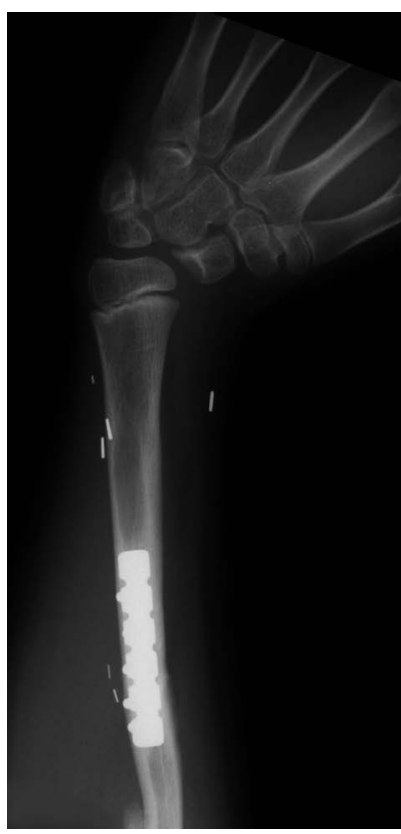

Fig. 9 Radial deviation of the wrist after resection of both forearm bones.

We observed that in all but 2 patients the new radius grew at the same rate as the ipsilateral ulna, thus maintaining the correct alignment of the wrist. Radial deviation of the wrist was indeed present in the patient where resection of both forearm bones was necessary ( $\bullet$ Fig. 9) and in a second patient who sustained a fracture with subsequent growth arrest ( $\bullet$ Fig. 10).

A progressive remodelling of the new-radius articular surface was evident in all the cases. Due to the new loading stresses the fibular had tended to become concave in shape with the advantages of improving the wrist stability and the range of motion.

Complications were observed both at donor and recipient sites. Although knee instability is a feared complication at the donor site, meticulous reconstruction of the lateral collateral ligament proved to be able to prevent this condition in all cases. By contrast, injuries to the small motor branches of the peroneal nerve are virtually unavoidable due to the anatomically intricate configuration of the personal nerve and the anterior tibial artery in this area.

When a major motor branch has to be severed to dissect the pedicle, direct neurotization or neurororraphy are recommended in order to reduce the risk of permanent palsy and foot drop. All patients presented a foot drop immediately after surgery. This condition is usually transitory but one patient in our series required a tendon transfer to recover ankle and toe dorsiflexion. A transitory foot drop is to be expected in all cases.

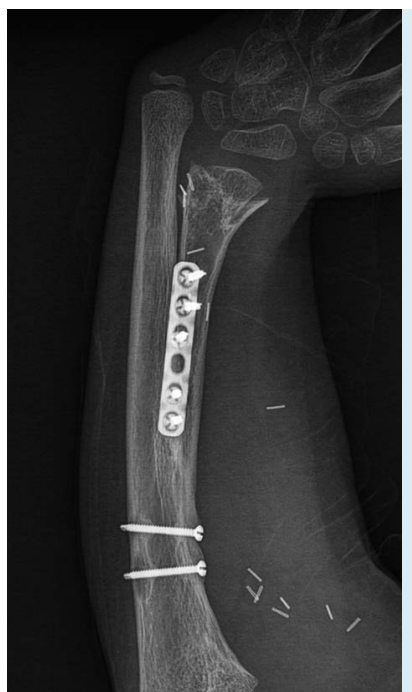

Fig. 10 Radial deviation of the wrist after post-traumatic growth arrest.

Fractures of the transplanted fibula occurred in 2 patients after significant direct trauma. Both fractures healed, but one required internal bone fixation.

\section{Discussion}

The first reports on free non-vascularized epiphyseal transplant date back to the end of nineteenth century [4-6]. All the attempts in the pre-microsurgical era gave discouraging results in terms of graft survival and growth. Nonetheless they identified that early revascularization of the growth plate was a crucial condition in determining the success of the procedure. Advances in microvascular surgery gave a new surge to experimental research. Bowen, Boyer, Nettelblad and others demonstrated the survival and the growth of the transplanted epiphysis after restoring the epiphyseal blood supply in animal models [7-15]. The procedure was brought into the clinical setting in the $1980 \mathrm{~s}$ [16-18].

The use of a number of different donor bones has been suggested in an attempt to minimize the morbidity at the donor site. Amongst them, the scapula, iliac crest, toe phalanges and proximal fibula have been described in a variety of clinical conditions to reconstruct several bones. The scapula and iliac crest, however, do not possess a true epiphysis but only an apophysis. Although their use has been reported in cases of lower limb reconstruction [19-22], their growth potential is less predictable when compared to an epiphyseal transfer. In addition, in the absence of a real articular surface the hyaline cartilage, which coats the apophysis, may suffer severe chondrolysis, and the consequent possibility of progressive arthritis, when transferred into an intra-articular location [22]. Furthermore, both scapula and iliac crest are flat bones that do not possess the tubular portion required to warrant a stable bone fixation in long diaphyseal reconstructions.

The best options for long bone reconstruction remain the proximal fibula, metatarsal, or toe phalanx epiphyseal transfer. For major reconstructions, the fibula is preferred since it provides a true epiphysis and a long diaphysis.

Because of anatomic congruency in size and shape between the fibula, the distal radius and proximal humerus, the free vascularized proximal fibula epiphyseal transfer is the ideal procedure for upper limb skeletal reconstruction. 


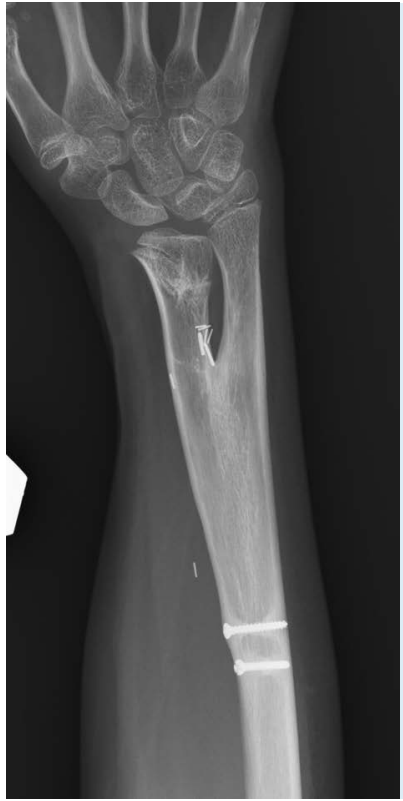

Fig. 11 Forearm reconstruction obtained with radio-ulnar synostosys. Both the new radial (fibular) and ulnar heads gradually modified their shape improving the joint stability.

Current indications for vascularized epiphyseal transfer include trauma, tumor and congenital disorders involving the growth plate of a long bone in children. Indications for reconstruction of the proximal humerus and the distal radius with such a procedure are quite well established. Occasionally though, this technique has been used for the hip and the knee reconstruction in very selected cases $[23,24]$. In our series of 8 cases of radial reconstruction, all the patients but one had a consistent and predictable axial growth after the transfer; all the grafts consolidated at the recipient site and underwent hypertrophy.

Failure of axial growth and premature fusion of the physis are the consequences of poor vascularization to the growth plate and might be related to the choice of the pedicle. Several options have been suggested in the past $[16,17,22,25,26]$ but among them, the anterior tibial artery seems to be the most reliable vascular pedicle to supply both the epiphysis and the proximal $2 / 3$ of the shaft as demonstrated by Taylor in 1988 [3]. Further experimental $[27,28]$ and clinical [29-35] studies confirmed that the recurrent branch of the anterior tibial artery supplies the proximal fibular growth plate while small musculoperiosteal perforators provide sufficient vascularization to a variable amount of the adjoining diaphysis.

At long-term follow-up (8-22 years) 6 out of the 7 surviving patients, showed continual and significant axial growth until the skeletal maturity was reached. The growth rate of the transplanted fibula was comparable to that of the ipsilateral ulna in all cases but one. Adaptive remodelling of the fibular head was observed in all cases according to any single anatomic configuration. The plasticity of the immature transplanted bone was particularly demonstrated in that case of radioulnar synostosys where both fibular and ulnar head gradually modified their shape, improving the joint stability ( $\bullet$ Fig. 11).

\section{Conclusions}

$\nabla$

Our long-term results confirm that a vascularized transfer of the proximal fibula provides a reliable and durable reconstruction of the distal radius in children. Even after 22 years, the reconstruct- ed joint resulted to be free of pain and degenerative changes thus maintaining a nearly normal range of motion. The described procedure is therefore highly recommended in cases of distal radius reconstruction in a growing child.

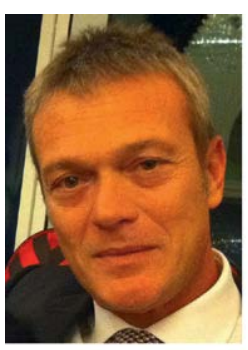

Marco Innocenti MD

Born 1956 in Florence (Italy). Marco Innocenti graduated cum Laude from University of Florence "Facolta' di Medicina e Chirurgia" in 1981. Residency in Orthopaedic e Traumatology Surgery in 1984, in Hand Surgery in 1987 and in Plastic Surgery in 2004 all 3 cum Laude.

Currently the Director of the "Plastic \& Reconstructive Microsurgery Department” of Careggi University Hospital in Florence (Italy).

Associate Professor of Plastic Surgery at the University of Florence and he also holds the position of Director of the Plastic Surgery residency program.

He acted as visiting professor at the "Henry Ford Health System" in Detroit (USA), at the "Duke University" in Durham (USA), at "Hirosaki Medical School" in Hirosaki (Japan), at Curtis Hand Center in Baltimore (USA), at "Victor Babes University of Medicine and Pharmacy" in Timisoara (Romania), at Larissa University (Greece), Beijing University (China) and Penn University in Philadelphia (USA). Since 2002 he's been consultant for Hand and Reconstructive Microsurgery at "Ospedale Pediatrico Meyer" in Florence (Italy), since 2006 at Gaetano Pini Orthopaedic Institute in Milan, and since 1998 at Rizzoli Institute in Bologna.

Dr. Innocenti's clinical work is focused on post traumatic and post oncological functional reconstruction of bone as well as soft tissue with a special interest in the Vascularized Proximal Fibular Epiphyseal Transfer in the growing individuals and the application of perforator flaps and propeller flaps.

His clinical interest extends also to the treatment of the congenital differences of the upper extremity.

He is past president of the Italian Society for Microsurgery (SIM) (2002-2005) for which he currently holds the position of European Delegate.

He is Associate Editor for the "Journal of Hand Surgery

(American)" and reviewer for the "Journal of Plastic Reconstructive and Aesthetic Surgery" and for the "Journal of Hand Surgery (European)"

\section{Conflict of interest: None}

\section{References}

1 Innocenti M, Delcroix L, Romano GF. Epiphyseal transplant: harvesting technique of the proximal fibula based on the anterior tibial artery. Microsurgery 2005; 25: 284-292

2 Innocenti M, Delcroix L, Manfrini $M$ et al. Vascularized proximal fibular epiphyseal transfer for distal radial reconstruction. J Bone Joint Surg Am 2005; 87 (Suppl 1, Pt 2): 237-246

3 Taylor GI, Wilson KR, Rees MD et al. The anterior tibial vessels and their role in epiphyseal and diaphyseal transfer of the fibula: experimental study and clinical applications. Br J Plast Surg 1988; 41: 451-469

4 Graham WC. Transplantation of joints to replace diseased or damaged articulations in hand. Am J Surg 1954; 88: 136-141 
5 Wenger HL. Transplantation of epiphyseal cartilage. Arch Surg 1954; 50: $148-151$

6 Wilson JN. Epiphyseal transplantation. A clinical study. J Bone Joint Surg 1966; 48A: 245-256

7 Bowen CVA, Ethridge CP, O'Brien BMcC et al. Experimental microvascular growth plate transfers. Part 1 - Investigation of vascularity. J Bone Joint Surg (Br) 1988; 70B: 305-310

8 Bowen CVA, O'Brien BMcC, Gumley GJ. Experimental microvascular growth plate transfers. Part 2 - Investigation of feasibility. J Bone Joint Surg (Br) 1988; 70B: 311-314

9 Bowen CVA, O'Brien BM. Experimental study of the microsurgical transfer of growth plates. Can J Surg 1984; 27: 446

10 Bowen CVA. Experimental free vascularized epiphyseal transplants. Orthopaedics 1986; 9: 893-898

11 Boyer MI, Bray PW, Bowen CVA. Epiphyseal plate transplantation: an historical review. Br J Plast Surg 1994; 47: 563-569

12 Donski PK, Carwell GR, Sharzer LA. Growth in revascularized bone grafts in young puppies. Plast Reconstr Surg 1979; 64: 239-243

13 Donski PK, O'Brien B. Free microvascular epiphyseal transplantation: an experimental study in dogs. Br J Plast Surg 1980; 33: 169-178

14 Nettelblad H, Randolph MA, Weiland AJ. Free microvascular epiphyseal plate transplantation. An experimental study in dogs. J Bone Joint Surg (Am) 1984; 66: 1421-1430

15 Nettelblad H, Randolph MA, Weiland AJ. Physiologic isolation of the canine proximal fibular epiphysis on a vascular pedicle. Microsurgery 1984; 5: 98-101

16 Pho RW, Patterson $M H$, Kour AK et al. Free vascularised epiphyseal transplantation in upper extremity reconstruction. J Hand Surg (Am) 1988; $13: 440-447$

17 Tsai TM, Ludwig L, Tonkin M. Vascularized fibular epiphyseal transfer: a clinical study. Clin Orthop 1986; 210: 228-234

18 Zhong-Wei C, Guang-Jian Z. Epiphyseal transplantation. In: Pho RW (ed.). Microsurgical technique in orthopaedics. London: Butterworths, 1988; $121-127$

19 Gilbert A, Mathoulin C. Vascularized bone grafts in children. Specifics and indications. Ann Chir Plast Esthet 2000; 45: 309-322

20 Teot L, Bossé JP, Pous JG. Vascularized bone transfer, including epiphyseal plate. In: Brunelli $\mathrm{G}$ (ed.). Textbook of microsurgery. Milan: Masson, 1988; 381-390

21 Teot L, Giovannini UM, Colonna MR. Use of free scapular crest flap in pediatric epiphyseal reconstructive procedures. Clin Orthop Relat Res 1999; 365: 211-220
22 Wood MB, Gilbert A (eds.). Microvascular bone reconstruction. London: Martin Dunitz, 1997; 85-89

23 Innocenti $M$, Manfrini $M$. Free vascularized proximal fibula for epiphyseal transfer. In: Reconstructive surgery of the lower extremity. Pu LL, Levine JP, Wei FC. Quality Medical Publishing, 2013; 985-998

24 Manfrini $M$, Innocenti $M$, Ceruso $M$ et al. Original biological reconstruction of the hip in a 4-year-old girl. Lancet 2003; 361: $140-142$

25 Bonnel $F$, Lesire $M$, Gomis $R$ et al. Arterial vascularization of the fibula microsurgical transplant techniques. Anatomia Clinica 1981; 3: $13-23$

26 Restrepo J, Katz D, Gilbert A. Arterial vascularization of the proximal epiphysis and the diaphysis of the fibula. Int J Microsurg 1980; 2: 48-51

27 Menezes-Leite MC, Dautel G, Duteille F et al. Transplantation of the proximal fibula based on the anterior tibial artery. Anatomical study and clinical application. Surg Radiol Anat 2000; 22: 235-238

28 Mozaffarian KL, Lascombes P, Dautel G. Vascular basis of free transfer of proximal epiphysis and diaphysis of fibula: an anatomical study. Arch Orthop Trauma Surg 2009; 129: 183-187

29 Amr SM, el-Mofty AO, Amin SN. Further experiences with transplantation of the head of the fibula. Handchir Mikrochir Plast Chir 2001; 33: $153-161$

30 de Gauzy JS, Kany J, Cahuzac JP. Distal fibular reconstruction with pedicled vascularized fibular head graft: a case report. J Pediatr Orthop B 2002; 11: 176-180

31 Innocenti M, Ceruso M, Manfrini $M$ et al. Free vascularised growth plate transfer after bone tumor resection in children. J Reconstr Microsurg 1998; $14:$ 137-143

32 Innocenti M, Delcroix L, Manfrini M et al. Vascularized proximal fibular epiphyseal transfer for distal radial reconstruction. J Bone Joint Surg Am 2004; 86A: 1504-1511

33 Innocenti $M$, Delcroix L, Romano GF et al. Vascularized epiphyseal transplant. Orthop Clin North Am 2007; 38: 95-101 vii

34 Medrykowski F, Barbary S, Gibert N et al. Vascularized proximal fibular epiphyseal transfer: two cases. Orthop Traumatol Surg Res 2012; 98: 728-732

35 Papadopulos NA, Weigand C, Kovacs L et al. The free vascularized fibular epiphyseal transfer: long-term results of wrist reconstruction in young patients. J Reconstr Microsurg 2009; 25: 3-13 